\title{
PENERAPAN METODE MIND MAPPING BERBANTUAN EDMODO BLENDED LEARNING UNTUK MENINGKATKAN KEMAMPUAN PEMECAHAN MASALAH MATEMATIS
}

\author{
Rahmawati \\ Fakultas MIPA Universitas PGRI Palembang \\ rahmawati.mipa@univpgri-palembang.ac.id
}

\begin{abstract}
ABSTRAK
Penelitian ini ditujukan untuk melihat adanya peningkatan kemampuan pemecahan masalah matematis siswa menggunakan model pembelajaran Mind Mapping dengan berbantuan edmodo blended learning. Populasi penelitian adalah siswa semester ganjil kelas VII MTs.Al-Hilaliyah Palembang. Jenis penelitian ini Quasi-Experimental. Data dalam penelitian ini adalah data kuantitatif yang diperoleh melalui Tes Kemampuan Pemecahan Masalah Matematis, yang dilakukan sebelum (pretes) dan sesudah (postes) kegiatan pembelajaran. Analisis data yang digunakan : melakukan analisis deskriptif data dan menghitung gain ternormalisasi (normalized gain) pretes dan postes. Pengujian persyaratan analisis adalah uji normalitas data dan uji homogenitas varians keseluruhan data kuantitaf, dan uji hipotesis yang dalam penelitian ini uji t, uji-t', uji Mann-Whitney U, uji ANAVA satu jalur atau uji Kruskal-Wallis. Pengujian hipotesis menggunakan SPSS-20 for Windows. Hasil analisis data diperoleh kesimpulan.1) peningkatan kemampuan pemecahan masalah matematis siswa yang mendapatkan pembelajaran dengan model Mind Mapping berbantuan edmodo blended learning lebih baik daripada siswa yang mendapatkan pembelajaran konvensional ditinjau dari (a) keseluruhan siswa (b)KAM siswa.
\end{abstract}

Kata kunci : Mind Mapping, Pemecahan Masalah Matematis, Edmodo Blended Learning

\begin{abstract}
This study aimed to see an increase in mathematical problem solving abilities of students using the Mind Mapping learning model assisted by edmodo blended learning. The research population were the seventh grade odd semester students of Palembang MT. Al-Hilaliyah. This type of research is Quasi-Experimental. The data in this researcher are distinguished by quantitative data that was obtained through the Mathematical Problem Solving Ability Test, which was conducted before (pretest) and after (posttest) learning activities. Quantitative data obtained through work results (answers) of students, observations, photos and videos, as well as the results of interviews with research subjects. Data analysis used: conducted descriptive analysis of data and calculated normalized gains (normalized gain) pretest and posttest. Testing requirements analysis is a normality test of data and a variance homogeneity test of all quantitative data, and hypothesis testing in this study t test, t-test, Mann-Whitney U test, one-way ANAVA test or Kruskal-Wallis test. Hypothesis testing using SPSS-20 for Windows. The results of the data analysis conclude.1) the improvement of mathematical problem solving abilities of students who get learning with the Mind Mapping model assisted by edmodo blended learning is better than
\end{abstract}


students who get conventional learning in terms of (a) all students (b) KAM students.

Keywords : Mind Mapping, Problem Solving Abilities of Students, Edmodo Blended Learning

\section{PENDAHULUAN}

Kemampuan pemecahan masalah matematis siswa didapatkan dari latihanlatihan yang sering dilakukan di kelas, mulai dari mengumpulkan teori-teori atau konsep-konsep pembelajaran yang terkait dengan masalah yang diberikan. Kemudian menciptakan langkah-langkah penyelesaian sehingga diperoleh solusi yang diinginkan. Hal ini sesuai dengan Permendiknas No.54 tahun 2013 bahwa siswa harus memiliki kemampuan faktual, konseptual dan prosedural dalam ilmu pengetahuan dan juga memiliki kemampuan pikir dan tindak yang efektif dan kreatif dalam ranah abstrak dan konkret sesuai dengan yang dipelajari di sekolah dan sumber lain sejenis. Dengan demikian siswa diharapkan memiliki kemampuan memahami masalah, menyelesaikan model dan menafsirkan solusi yang diperoleh.

Banyak faktor yang mempengaruhi hasil belajar siswa dalam memecahkan suatu masalah. Menurut Faelasofi (2015) bahwa sebagian besar siswa belum sepenuhnya mampu mendeskripsikan apa yang diketahui dan ditanyakan pada permasalahan yang akan diselesaikan, siswa masih kurang mampu menghubungkan gambar kedalam ide matematika dari pemahaman dan pengetahuan yang ia miliki. Menurut Novianti (2018) bahwa rendahnya pemahaman mahasiswa dalam mengaitkan hubungan konsep matematika dengan topik lain disebabkan pendidikan yang diberikan masih cenderung aktif menggunakan model pembelajaran konvensional,sehingga mengakibatkan siswa tidak mampu menghubungkan konsep satu dengan yang lainnya. Ditambahkan oleh Purwaningsih (2017) bahwa kurangnya pemahaman konsep dan kemampuan bernalar serta kurangnya mahasiswa berpikir secara logis dan sistematis menjadi faktor penyebab rendahnya kemampuan pemcahan masalah matematis. Menurut Sudarman (2009) dalam kegiatan belajar mengajar (KBM), seorang guru memiliki peranan yang sangat penting. Kehadiran guru dalam proses pembelajaran masih tetap memegang peranan penting. Oleh karena itu guru perlu memiliki keterampilan dalam memilih metode yang tepat ketika menyampaikan suatu materi kepada siswanya agar menjadi lebih menarik, tidak mengalami kebosanan dan dapat menerima materi tersebut dengan mudah, yang tentu hal tersebut akan menunjang prestasi belajarnya, oleh karena itu guru merupakan salah satu penentu berhasil atau tidaknya siswa dalam mencapai tujuan pembelajaran.

Kesumawati (2010) menyatakan kemampuan pemecahan masalah matematis adalah kemampuan megidentifikasi unsur-unsur yang diketahui, ditanyakan, dan kecukupan unsur yang diperlukan, mampu membuat atau menyusun model matematika, dapat memilih dan mengembangkan strategi pemecahan, mampu menjelaskan dan memeriksa kebenaran jawaban yang diperoleh.

Dahar (2011) mengemukakan bahwa pemecahan masalah merupakan suatu kegiatan manusia yang menggabungkan konsep-konsep dan aturan-aturan yang telah diperoleh sebelumnya, dan tidak sebagai suatu keterampilan generik. Menurut Arthur (2008: 1) pemecahan masalah merupakan bagian dari berpikir. Sebagai 
bagian dari berpikir, latihan pemecahan masalah dapat meningkatkan kemampuan berpikir sebagai proses kognitif tingkat tinggi yang memerlukan modulasi dan kontrol lebih dari keterampilan rutin atau dasar.

Pendapat di atas mengisyaratkan bahwa dalam memecahkan masalah, seseorang tidak hanya memerlukan keterampilan rutin atau dasar, tetapi juga berbagai keterampilan lainnya untuk mengatur semua proses berpikirnya agar dapat memecahkan masalah yang dihadapi. Pengaturan dimaksud dapat dilakukan dengan mengontrol semua pengetahuan yang dimilikinya terkait dengan masalah tersebut dan memilahnya agar dapat menemukan cara terbaik untuk memecahkannya. Kecepatan dan ketepatan dalam memilih dan memilah pengetahuan yang relevan sangat menentukan dalam memecahkan masalah. Kemampuan seperti ini penting dimiliki setiap mahasiswa agar terbiasa menghadapi berbagai masalah yang semakin kompleks, baik pada masalah matematika maupun di luar matematika. Di sinilah peran matematika sebagai alat pemecah masalah (tools of problem solving). Dalam NCTM (Rahmawati dan Jayanti, 2017) dikatakan, pemecahan masalah adalah bagian integral dari semua pembelajaran matematika.

Suherman, dkk (2003:83) mengatakan bahwa pemecahan masalah merupakan unsur terpenting dari pembelajaran matematika. Melalui pemecahan masalah ini aspek-aspek kemampuan matematika seperti penerapan aturan, penemuan pola, penggeneralisasian, komunikasi matematik dan lain-lain dapat dikembangkan secara baik. Kemampuan pemecahan masalah matematis merupakan kemampuan yang menjadi target pembelajaran matematika dan terukur. Menurut Tim Pustaka Yustisia (2007: 389), pemecahan masalah merupakan kompetensi strategis yang ditunjukkan siswa dalam memahami, memilih pendekatan dan strategi pemecahan masalah, dan menyelesaikan model untuk menyelesaikan masalah. Indikator yang menunjukkan pemecahan masalah, yakni (1) menunjukkan pemahaman masalah, (2) mengorganisasi data dan memilih informasi yang relevan dalam pemecahan masalah, (3) menyajikan masalah secara matematis dalam berbagai bentuk, (4) memilih pendekatan dan metode pemecahan masalah secara tepat, (5) mengembangkan strategi pemecahan masalah, (6) membuat dan menafsirkan model matematis dari suatu masalah, dan (7) menyelesaikan masalah yang tidak rutin.

Dengan demikian dibutuhkan model pembelajaran yang membantu siswa dalam mempelajari suatu konsep sehingga dapat meningkatkan kemampuan pemecahan masalah matematis siswa menjadi lebih baik. Salah satu model adalah Mind Mapping. Istarani (2011:55), menyatakan bahwa Mind Mapping adalah konsep sebagai dasar utama berpijak dan masalah sebagai bahan dasar pijakan yang dibicarakan dalam pelajaran. Pada sisi lain Mind Mapping merupakan pembelajaran yang akan melatih alur pikir mahasiswa menuju satu titik, yang merupakan fokus suatu kajian. Jika mahasiswa dapat menfokuskan pikiran pada kajian itu, maka akan berkonsentrasi dan melakukan pembelajaran dengan baik sehingga pada akhirnya memiliki keterampilan dalam berpikir. Mind Mapping adalah proses menuangkan pikiran dalam memahami dan menyerap informasi untuk mengembangkan suatu ide menjadi ide-ide yang lebih rinci (Mento, 1999). Huda (2016:307) mengatakan bahwa mind mapping bisa digunakan untuk membantu penulisan esai atau tugas-tugas yang berkaitan dengan penguasaan konsep.

Beberapa studi melaporkan keunggulan model Mind Mapping dari pada pembelajaran konvensional. Menurut Purwaningsih (2017) bahwa ada pengaruh metode mind mapping terhadap kemampuan pemecahan masalah matematis. 
Menurut Nurdamayanti (2018) bahwa pembelajaran dengan menerapkan metode mind mapping dapat berdampak positif terhadap aktivitas, respon, dan hasil belajar siswa. Menurut Novianti (2018) bahwa media pembelajaran Mind Mapping dapat mengaktifkan pembelajaran mahasiswa. Juga menurut Jones (2012) bahwa Mind Mapping membantu siswa mempelajari informasi dengan mengelompokkannya dan membiarkan siswa untuk memvisualisasikan materi pelajaran sesuai pikiran mereka

Model pembelajaran blended learning menurut Garrison \& Vaughan (2008:5) merupakan model pembelajaran yang mengkombinasikan antara pembelajaran tatap muka dan pembelajaran online. Siswa yang belajar dapat mengikuti pembelajaran dengan tatap muka dan pembelajaran online di rumah. Blended learning dapat mengurangi biaya dengan menempatkan ruang kelas di ruang online dan pada dasarnya menggantikan buku teks dengan perangkat elektronik yang sering dibawa siswa ke kelas.

Salah satu aplikasi yang bisa digunakan dalam pembelajaran dengan model blended learning adalah Edmodo. Media pembelajaran elektronik merupakan perangkat penting yang dapat digunakan oleh untuk meningkatkannya motivasi dan pendidikan siswa (Mateo, Rey, \& Hernández, 2010). Dalam perkembangannya media pembelajaran elektronik masih sangat jarang digunakan dalam dunia pendidikan, khususnya media pembelajaran elektronik berbasis edmodo. Edmodo adalah alat media pembelajaran elektronik sederhana yang digunakan untuk menyajikan isi pelajaran, biasanya semua sistem operasi smartphone ini menyediakan alat yang berguna bagi siswa dan guru untuk berinteraksi online di luar kelas dimana saja, kapan saja (Hourdequin, 2014). Media pembelajaran tersebut berbasis website yang mudah untuk digunakan. Hal ini karena tampilan dan fitur yang tersedia dalam edmodo mengikuti perkembangan tampilan dari media jejaring sosial yang sering digunakan siswa.

Beberapa penelitian yang telah dilakukan dengan menggunakan aplikasi edmodo menurut Rismayanti (2012), fitur ini berfungsi memberi kesempatan kepada orangtua/wali masing-masing siswa dapat bergabung memantauaktivitas belajar dan prestasi putra-putrinya, guru harus mengakses kode untuk orang tua siswa dan kemudian membagikannya pada masing-masing orangtua/wali. Akses kode untuk orang tua siswa dapat diperoleh dengan mengklik nama kelas. Menurut Tripathi (2016), model pengajaran yang efisien didasarkan pada pendekatan Blended Learning dan Edmodo dimana kita dapat mengintegrasikan setiap elemen dari Efektivitas Pembelajaran Blended Menggunakan LMS-Edmodo dalam Pengajaran Ekonomi di Tingkat Menengah Tinggi. Inel (2017) menyatakan hasil yang diperoleh dari studi telah menunjukkan bahwa aplikasi Edmodo, yang memberikan kesempatan untuk membuat ruang kelas virtual, dapat digunakan dalam pendidikan guru untuk menciptakan koneksi antara kursus teori dan praktis. Selain itu, seorang siswa dapat berpartisipasi dalam kelas teknologi sesuai pilihan waktu dan waktunya, dan dapat belajar dengan langkahnya sendiri.

Tujuan penelitian ini adalah untuk mengetahui apakah peningkatan kemampuan pemecahan masalah matematis siswa kelas 7 semester ganjil tahun ajaran 2018/2019 MTs. Al-Hilaliyah Palembang yang mendapat pembelajaran dengan model mind mapping berbantuan edmodo blended learning lebih baik daripada siswa yang mendapat pembelajaran konvensional ditinjau dari (a) keseluruhan siswa, dan (b) KAM (tinggi, sedang, dan rendah) siswa. 


\section{METODE}

Penelitian ini merupakan penelitian Quasi-Experimental karena sampel tidak dikelompokkan secara acak, tetapi diterima apa adanya (Ruseffendi, 2005). Pemilihan tipe Quasi-Experimental ini dengan pertimbangan bahwa kelas yang ada telah terbentuk sebelumnya dan siswa telah mendaftar sesuai dengan kurikulum yang ada, sehingga tidak dilakukan lagi pengelompokan secara acak.

Pada penelitian ini, sampel penelitian diberi perlakuan dan selanjutnya ingin diketahui pengaruh perlakuan tersebut. Perlakuan tersebut adalah pembelajaran dengan menggunakan model mind mapping berbantuan edmodo blended learning yang diterapkan pada kelas eksperimen. Kemampuan yangdiukur pada penelitian ini adalah kemampuan pemecahan masalah matematis (KPMM).

Desain penelitian yang digunakan adalah desain kelompok kontrol pretes dan postes non-ekivalen atau Nonequivalent Pre-Test and Post-Test Control-Group Design (Creswell, 2009). Secara ringkas desain eksperimen tersebut dapat digambarkan sebagai berikut.

Keterangan:

$$
\begin{array}{lll}
O_{1} & X & O_{2} \\
\hline O_{1} & O_{2}
\end{array}
$$

$O_{1} \quad$ : Pretes tentang pemecahan masalah matematis

$\mathrm{O}_{2} \quad$ : Postes tentang pemecahan masalah matematis

$X \quad$ : Perlakuan berupa pembelajaran dengan model mind mapping berbantuan edmodo blended learning

Variabel dalam penelitian ini terdiri dari variabel bebas, variabel terikat, dan variabel kontrol. Variabel bebasnya adalah pembelajaran dengan menggunakan Model Mind Mapping berbantuan edmodo blended learning (MMMBL). Variabel terikatnya adalah kemampuan pemecahan masalah matematis (KPMM). Variabel kontrolnya adalah kemampuan awal siswa (KAM). Berdasarkan kemampuan awal siswa, diperoleh tiga kategori KAM yaitu: kategori KAM rendah, KAM sedang, dan KAM tinggi. Kemampuan awal siswa diperoleh dari hasil tes tentang materi yang akan diberikan. Variabel terikat dikaji secara lebih komprehensif, ditinjau dari pembelajaran, KAM, dan keseluruhan siswa. Keterkaitan antara variabel-variabel penelitian yaitu variabel bebas, variabel terikat, dan variabel kontrol dinyatakan dalam bentuk model Weiner pada Tabel 1 .

Tabel 1. Kemampuan Pemecahan Masalah Matematis, Pembelajaran, dan Kemampuan Awal Mahasiswa

\begin{tabular}{ccc}
\hline Kelompok & \multicolumn{2}{c}{ KPMM } \\
\cline { 2 - 3 } KAM & MMMBL & PK \\
\hline Rendah $(\mathrm{R})$ & KPM-MMMBL-R & KPMM-PK-R \\
Sedang (S) & KPM-MMMBL-S & KPMM-PK-S \\
Tinggi (T) & KPM-MMMBL-T & KPMM-PK-T \\
Keseluruhan(L) & KPM-MMMBL-L & KPMM-PK-L \\
\hline
\end{tabular}

Keterangan :

KPMM : Kemampuan Pemecahan Masalah Matematis

MMMPBL : Pembelajaran dengan menggunakan model Mind Mapping 


\section{Berbantuan Edmodo Blended
: Pembelajaran konvensional}

Populasi dalam penelitian ini adalah siswa kelas VII Semester Ganjil Tahun Ajaran 2018/2019 MTs. Al-Hilaliyah Palembang. Sedangkan sampel adalah siswa kelas VIIa dan VIIb. Teknik pengambilan sampel yang digunakan adalah purposive sampling.

Untuk menetapkan sampel penelitian, ditempuh langkah-langkah berikut:

1. Mendata siswa kelas VII pada semester ganjil TA 2018/2019. Siswa sudah terdistribusi dalam rombongan belajar (rombel) oleh pihak sekolah tanpa kriteria khusus. Jadwal pelajaran dan administrasi yang mendukungnya telah diatur melalui sekolah. Oleh karena itu, tidak dilakukan pengacakan terhadap siswa secara individu, tapi menerima subjek apa adanya di setiap kelas pembelajaran.

2. Memilih 2 kelas eksperimen secara purposive sampling dengan mempertimbangkan efiseinsi waktu, biaya, dan persiapan penelitian. Kelas yang terpilih secara purposive sampling adalah kelas A dan B.

3. Menguji kesetaraan kelas yang terpilih yaitu kelas A dan B melalui gambaran kualitas KAM pada kelas-kelas tersebut untuk ditetapkan sebagai eksperimen (pembelajaran dengan model Mind Mapping berbantuan edmodo blended learning dan kelas kontrol (pembelajaran konvensional).

Data dalam penelitian ini berupa data kuantitatif dan dilengkapi dengan data kualitatif. Data kuantitatif diperoleh melalui Tes Kemampuan Pemecahan Masalah Matematis, yang dilakukan sebelum (pretes) dan sesudah (postes) kegiatan pembelajaran. Data kualitatif diperoleh melalui hasil pekerjaan (jawaban) mahasiswa. Data kualitatif dianalisis secara deskriptif untuk mendukung kelengkapan data kuantitatif.

Data kuantitatif ditabulasi dan dianalisis melalui tiga tahap, yaitu:

1. Tahap pertama: melakukan analisis deskriptif data dan menghitung gain ternormalisasi (normalized gain) pretes dan postes.

2. Tahap kedua: menguji persyaratan analisis statistik parametrik yang diperlukan sebagai dasar dalam pengujian hipotesis. Pengujian persyaratan analisis dimaksud adalah uji normalitas data dan uji homogenitas varians keseluruhan data kuantitatif.

3. Tahap ketiga: menguji keseluruhan hipotesis. Secara umum, uji hipotesis yang digunakan dalam penelitian ini adalah uji t, uji-t', uji Mann-Whitney U, uji ANAVA satu jalur atau uji Kruskal-Wallis. Keseluruhan pengujian hipotesis tersebut menggunakan paket Program statistik SPSS-20 for Windows

\section{HASIL DAN PEMBAHASAN}

Untuk memperoleh gambaran hasil KPMM siswa, data dianalisis secara deskriptif untuk mengetahui rerata dan simpangan baku skor pretes, postes dan ngain KPMM siswa berdasarkan pembelajaran, KAM, dan secara keseluruhan. Soal untuk tes KPMM terdiri dari 4 soal yang terdiri dari 10 indikator yang dianalisis. Peningkatan KPMM siswa berdasarkan pembelajaran (MMMBL dan PK), KAM (tinggi, sedang, dan rendah), dan keseluruhannya secara lebih jelas. Sebelum 
melakukan uji tersebut terlebih dahulu dilakukan uji prasyarat analisis, yaitu uji normalitas data dan uji homogenitas varians. Rangkuman hasil uji normalitas disajikan pada Tabel 2 dan uji homogenitas pada Tabel 3.

Tabel 2. Uji Normalitas Data Peningkatan Kemampuan Pemecahan Masalah Matematis Berdasarkan Pembelajaran dan KAM

\begin{tabular}{lccccc}
\hline $\begin{array}{c}\text { Kelompok } \\
\text { KAM }\end{array}$ & Pembelajaran & $N$ & K-S & Sig & $\mathrm{H}_{\mathrm{o}}$ \\
\hline \multirow{2}{*}{ Keseluruhan } & MMMBL & 36 & 1.269 & 0.080 & Diterima \\
& PK & 34 & 0.727 & 0.666 & Diterima \\
\multirow{2}{*}{ Tinggi } & MMMBL & 8 & 1.104 & 0.175 & Diterima \\
& PK & 4 & 0.534 & 0.938 & Diterima \\
Sedang & MMMBL & 24 & 1.183 & 0.122 & Diterima \\
& PK & 21 & 0.631 & 0.820 & Diterima \\
\multirow{2}{*}{ Rendah } & MMMBL & 4 & 0.802 & 0.541 & Diterima \\
& PK & 9 & 0.411 & 0.996 & Diterima
\end{tabular}

$\mathrm{H}_{\mathrm{o}}$ : Data peningkatan KPMM berdasarkan pembelajaran berdistribusi normal

Tabel 3. Uji Homogenitas Varians Populasi Peningkatan KPMM Berdasarkan Pembelajaran KAM

\begin{tabular}{lccc}
\hline Kelompok KAM & $\begin{array}{c}\text { Statistik } \\
\text { Levene (F) }\end{array}$ & Sig. & $\mathrm{H}_{\mathrm{o}}$ \\
\hline Keseluruhan & 0.001 & 0.982 & Diterima \\
Tinggi & 2.032 & 0.184 & Diterima \\
Sedang & 0.162 & 0.689 & Diterima \\
Rendah & 4.843 & 0.052 & Diterima \\
\hline
\end{tabular}

$\mathrm{H}_{\mathrm{o}}$ : Varians antar kelompok data peningkatan KPMM homogen

Pada Tabel 2 dan Tabel 3 terlihat bahwa data peningkatan KPMM pada kelompok MMMBL dan PK berdistribusi normal dan variansnya homogen. Karena itu, untuk mengetahui apakah terdapat perbedaan rerata peningkatan KPMM antara kedua kelompok pembelajaran (MMMBL dan PK) dapat dilakukan dengan menggunakan uji-t. Rangkuman hasil uji t dapat dilihat pada Tabel 4 berikut:

Tabel 4.Uji Perbedaan Rerata Data Peningkatan KPMM Berdasarkan Pembelajaran dan KAM

\begin{tabular}{cccccc}
\hline $\begin{array}{c}\text { Kelompok } \\
\text { KAM }\end{array}$ & Pembelajaran & Rerata & $T$ & Sig. & $\mathrm{H}_{\mathrm{o}}$ \\
\hline
\end{tabular}




\begin{tabular}{lccccc}
\hline \multirow{2}{*}{ Keseluruhan } & MMMBL & 0.4545 & -5.826 & 0.000 & Ditolak \\
& PK & 0.3190 & & & \\
Tinggi & MMMBL & 0.5512 & -0.899 & 0.028 & Ditolak \\
& PK & 0.4042 & & & \\
\multirow{2}{*}{ Sedang } & MMMBL & 0.4266 & -3.608 & 0.001 & Ditolak \\
& PK & 0.3278 & & & \\
Rendah & MMMBL & 0.428 & -4.756 & 0.001 & Ditolak \\
& PK & 0.2605 & & & \\
\hline
\end{tabular}

Pada tabel 4 terlihat bahwa secara keseluruhan siswa yang mendapatkan pelajaran dengan menggunakan model mind mapping berbantuan edmodo blended learning menunjukkan peningkatan KPMM yang lebih tinggi daripada siswa yang mendapatkan pembelajaran konvensional, dari perhitungan nilai t dengan rumus uji-t. Berdasarkan hasil perhitungan, diperoleh thitung kelas model pembelajaran Mind Mapping berbantuan edmodo blended Learning yaitu didapatkan nilai T hitung -5,82 dengan nilai tanda $(\operatorname{sig} 0,000)<5 \%$, artinya terdapat perbedaan perlakuan terhadap kelas kontrol. di kelas VII Semester Ganjil Tahun Ajaran 2018/2019 MTs. AlHilaliyah Palembang. Siswa yang mendapatkan pembelajaran dengan menggunakan model mind mapping menunjukan rerata postes yang lebih besar daripada mahasiswa yang mendapatkan pembelajaran konvensional yaitu 0,4545 > 0,3190.

Selanjutnya diperlihatkan bagaimana kemampuan pemecahan masalah matematis siswa melalui jawaban yang dituliskan pada lembar tes. Berikut ini salah satu jawaban yang diberikan siswa.
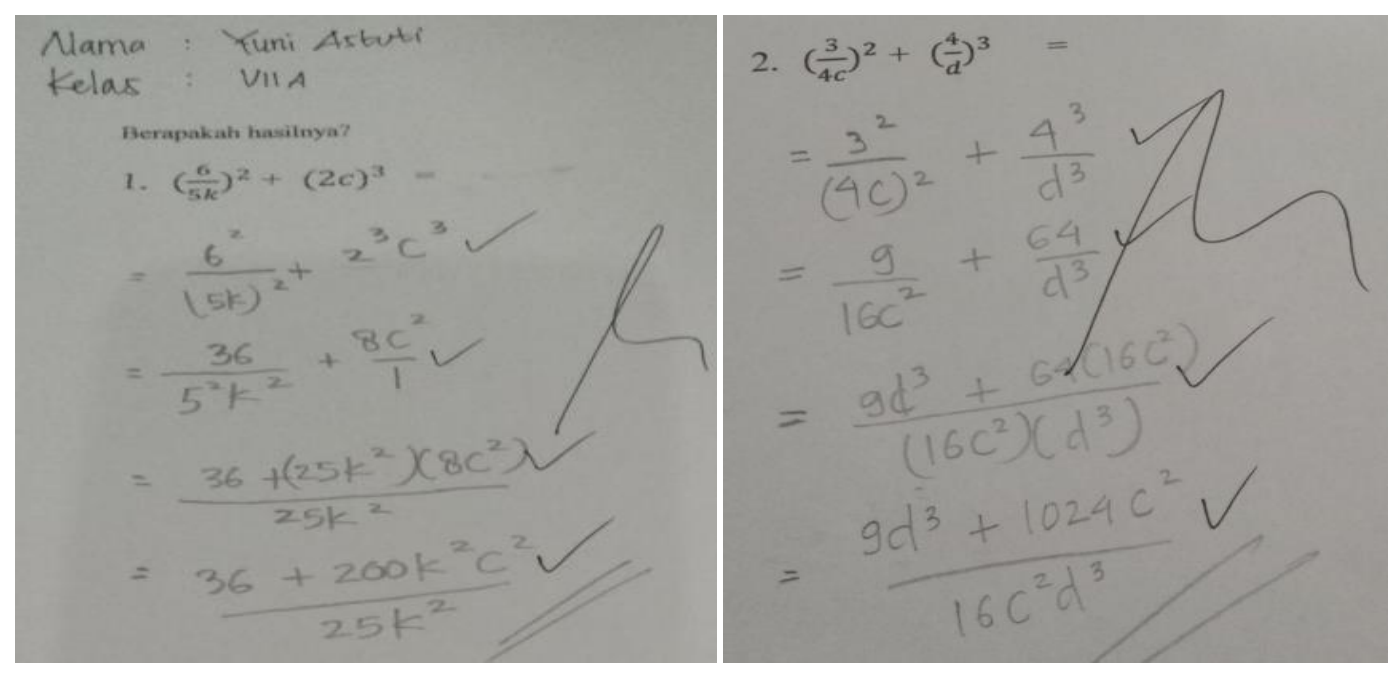

Terlihat bahwa siswa mampu menyelesaikan perhitungan dengan langkahlangkah penyelesaian yang benar. Logika penyelesaian sesuai dengan aturan yang berlaku pada bilangan pangkat dan penjumlahan dari pembagian. Urutan langkah sudah tepat dan tidak rancu.

Jawaban-jawaban siswa yang lain pun demikian. Kemampuan pemecahan masalah mereka cukup baik. Soal-soal materi bilangan pangkat diselesaikan sesuai 
dengan prosedur dan urutan langkah yang benar.

Dari hasil observasi juga menunjukkan bagaimana antusias siswa dalam mengikuti pembelajaran yang menggunakan metode Mind Mapping. Mereka nampaknya mengikuti dengan semangat penerapan metode ini. Dengan Mind Mapping mereka terbiasa memetakan arah atau alur pikiran mereka untuk menyelesaikan suatu masalah. Dimulai dari sesuatu yang utama dulu, baru mencari cabang-cabang pemetaan, satu-persatu, hingga menuju hasil yang diinginkan. Dengan metode Mind Mapping ini, siswa akan terbiasa mengolah pikiran mereka secara terperinci dan terarah.

Ditambah lagi dengan menggunakan Edmodo Blended Learning. Guru dengan mudah membuat dan mengelola kelas virtual sehingga siswa dapat terhubung dengan teman sekelasnya dan guru, kapan saja dan dimana saja. Mereka tidak terikat oleh waktu dan tempat yang terkadang mengekang untuk belajar. Mereka dapat mengikuti pembelajaran melalui handphone yang dibawa, sehingga dapat mengikuti pembelajaran dengan fleksibel.

Pembelajaran dalam kelas virtual bukanlah menggantikan pembelajaran tatap muka yang dilaksanakan di kelas, tetapi dengan memanfaatkan kelas virtual akan didapatkan tambahan atau pengayaan materi yang akan melengkapi pembelajaran konvensional. Dengan model pembelajaran Blended Learning, siswa akan didorong untuk lebih aktif dan kreatif. Siswa diharapkan dapat mencari, membaca, dan memahami materi dari berbagai sumber belajar digital, di samping untuk menyimpulkan, mencipta, dan berbagi baik pengetahuan yang telah didapatkan maupun hasil karya yang telah dibuat kepada sesama siswa. Siswa juga diharapkan mampu untuk berdiskusi dan bekerja sama dalam kelompok secara virtual. Tentunya pemanfaatan media pembelajaran selalu memiliki pengaruh positif yang cukup kuat dan signifikan terhadap motivasi belajar siswa, apalagi media pembelajaran berbasis edmodo.

\section{SIMPULAN DAN SARAN}

Berdasarkan data hasil pengujian hipotesis, maka dari hasil penelitian ini dapat disimpulkan bahwa: 1) Peningkatan kemampuan pemecahan masalah matematis siswa yang mendapat pembelajaran dengan menggunakan model Mind Mapping berbantuan edmodo blended learning lebih baik daripada siswa yang mendapat pembelajaran konvensional ditinjau dari keseluruhan, dan 2) Peningkatan kemampuan pemecahan matematis matematis siswa yang mendapat pembelajaran dengan menggunakan model Mind Mapping berbantuan edmodo blended learning lebih baik daripada siswa yang mendapat pembelajaran konvensional ditinjau dari KAM siswa.

Berdasarkan hasil penelitian, dapat disarankan hal-hal sebagai berikut: 1) Pembelajaran dengan menggunakan model mind mapping berbantuan edmodo blended learning hendaknya menjadi alternatif pembelajaran di universitas dan di sekolah; terutama untuk meningkatkan kemampuan pemecahan matematis siswa, dan 2) Bagi peneliti yang akan menerapkan pembelajaran dengan menggunakan model mind mapping berbantuan edmodo blended learning dan mengembangkan kemampuan pemecahan masalah matematis, agar dapat digali lebih jauh lagi tentang perbandingan setiap aspek kemampuan pemahaman matematis (pemahaman konsep meliputi menginterpretasikan, mengklasifikasikan objekobjek menurut sifat-sifat tertentu, menjelaskan, merumuskan, dan melakukan perhitungan dalam matematika, dan pemahaman relasional meliputi kemampuan membandingkan atau menggunakan matematika dalam konteks matematika di dalam maupun di luar matematika). 


\section{DAFTAR PUSTAKA}

Arthur, L. B. 2008. Problem Solving. U.S.: Wikimedia Foundation, Inc. [Online]. Tersedia: http://en.wikipedia.org/wiki/ProblemSolving._[7 April 2008].

Creswell. 2009. Research Design Pendekatan Kualitatif, Kuantitatif, dan Mixed. Edisi Ketiga. Yogyakarta: Pustaka Pelajar.

Dahar, R., W. 2011. Teori-teori Belajar dan Pembelajaran. Jakarta: Erlangga.

Faelasofi, Rahma. dkk. 2015. Metode Pembelajaran Mind Mapping untuk Meningkatkan Kemampuan Komunikasi Matematik Siswa dalam Pemecahan Masalah Matematika. Jurnal e-DuMath, Vol. 1(2) : 122-136.

Garrison, D. R., \& Vaughan, N. D. 2008. Blended Learning in Higher Education: Framework, principles and guidelines. San Fransisco: Josey-Bass.

Hourdequin, P. 2014. Edmodo: A Simple Tool for Blended Learning. The Language Teacher38.

Huda, Miftahul. 2016. Model-Model Pengajaran dan Pembelajaran. Yogyakarta: Pustaka Pelajar.

Inel Didem, Ekici. 2017. The Use Of Edmodo In Creating An Online Learning Community Of Practice For Learning To Teach Science. Malaysian Online Journal internasional of Educational Sciencesi, Vol. 5(2).

Istarani. 2011. Kumpulan 39 Metode Pembelajaran. Medan: CV. Iscom Medan.

Jones, B.D., Ruff, C., Snyder, J.D., Petrich, B., \& Koonce, C. 2012. The Effect of Mind Mapping Activities on Student's Motivation. International Journal for the Scholarship of Teaching and Learning, Vol. 6(1).

Kementerian Pendidikan dan Kebudayaan Republik Indonesia. 2013. Peraturan Kementerian Pendidikan dan Kebudayaan No. 54 Tahun 2013 tentang Standar Kompetensi Lulusan Pendidikan Dasar dan Menengah. Jakarta: Kementerian Pendidikan dan Kebudayaan.

Kesumawati, Nila. 2010. Peningkatan Kemampuan Pemahaman, Pemecahan Masalah, dan Disposisi Matematis Siswa SMP Melalui Pendekatan Matematika Realistik Indonesia. Disertasi tidak diterbitkan. Bandung: Universitas Pendidikan Indonesia.

Mateo, Rey, P. d., \& Hernández. 2010. Student motivation and cross-curricular development through e-learning applied to cooperation. The Future of Global Learning Engineering Education (EDUCON).

Mento, dkk. 1999. Mind Mapping in Executive Education Applications and Outcomes. The Journal of Management Development, Vol. 18(4).

Novianti. 2018. Pengaruh Model Pembelajaran Mind Mapping Terhadap Peningkatan Kemampuan Pemecahan Masalah Mahasiswa Matematika Semester III FKIP Umuslim Pada Mata Kuliah Program Linear. Variasi : Majalah Ilmiah Universitas Almuslim, Vol. 10(2) : 25-28.

Nurdamayanti, Aulia. 2018. Penerapan Metode Mind Mapping Pada Pembelajaran Matematika Siswa SMPN 48 Surabaya. Buana Matematika: Jurnal Ilmiah Matematika dan Pendidikan Matematika, Vol. 8(1) : 17-24.

Purwaningsih, Dian. 2017. Pengaruh Metode Mind Mapping dan Keterampilan Proses Terhadap Kemampuan Pemecahan Masalah Matematis Mata Kuliah Struktur Aljabar. Jurnal Aksioma, Vol. 8(1) : 1-8.

Rahmawati dan Jayanti. 2017. Pengaruh Model Pembelajaran Blended Learning Menggunakan Probing Prompting Terhadap Hasil Belajar Mahasiswa Pada Mata Kuliah Persamaan Diferensial. Jurnal Nabla Dewantara, Vol. 2(2) : 82- 
INDIKTIKA (Jurnal Inovasi Pendidikan Matematika)

Desember 2018, Volume 1 No.1 Hal. 44-54

97.

Rismayanti, Anti. 2012. Mengenal Lebih Dekat Edmodo Sebagai Media E-Learning dan Kolaborasi. [Online]. http://download.smknl-majakengka.sch.id. [20 Mei 2012].

Ruseffendi. 2005. Dasar-dasar Penelitian Pendidikan dan Bidang Non-eksakta Lainnya. Bandung: Tarsito.

Sudarman. 2009. Peningkatan Pemahaman dan Daya Ingat Siswa Melalui Strategi Preview, Question, Read, Reflect, Recite, dan Review (PQ4R). Jurnal Pendidikan Inovatif, Vol. 4(2) : 67-72.

Suherman, E. dkk. 2003. Evaluasi Pembelajaran matematika. Bandung: JICA UPI.

Tim Pustaka Yustisia. 2007. Panduan Lengkap KTSP (Kurikulum Tingkat SatuanPendidikan) SD, SMP, dan SMA. Seri Perundangan. Cetakan Pertama. Yogyakarta: Pustaka Yustisia.

Tripathi, H. 2016. Effectiveness of Blended Learning Using LMSEdmodoin Teaching Economics at Higher Secondary Level. International Journal of Indian Psychology, Vol. 3(3), No. 10, DIP: 18.01.180/20160303, ISBN: 978-1365-19879-3. 